\title{
APRESENTAÇÃO - CONTRIBUIÇÕES PARA UMA HISTORIOGRAFIA DA TRADUÇÃO
}

\author{
John Milton e Marcia A. P. Martins
}

A primeira parte desta Apresentação usa como base o artigo de Lieven D’hulst, "Why and How to Write Translation Histories” (2001), publicado em volume da revista CROP sobre o tema "Emerging Views on Translation History in Brazil”. No começo do artigo D’hulst coloca quatro razões fundamentais para valorizar os estudos historiográficos sobre a tradução: i) a história abre os olhos do estudioso da tradução e expande seus conhecimentos; ii) a história fornece ao estudioso flexibilidade intelectual para adaptar suas ideias a novos pontos de vista; iii) o conhecimento da história da tradução impede que o estudioso siga cegamente uma única teoria, fechando-se, assim, a outras; iv) o conhecimento da história da tradução demonstra os relacionamentos subjacentes entre práticas e abordagens.

D’hulst divide seu artigo em várias seções, cada uma com um título em latim. O primeiro é Quis? (Quem?) Quem foram os tradutores? Exerciam outras profissões ou dependiam somente de traduções? O que sabemos sobre as suas vidas? Quantos anos tinham? A quais classes sociais pertenciam? Quantos eram mulheres? Tinham algum tipo de treinamento para seu ofício de tradutor? Traduziam conforme certos conceitos ou poéticas? Eram estrangeiros ou filhos de estrangeiros? Para utilizar o termo bourdieusiano, como era o seu habitus tradutológico? (Simeoni, 1998).

Seria interessante ver um volume brasileiro nos moldes de Translators through History (Delisle \& Woodsworth, 1995), Portrait des Traducteurs (Delisle, 1999) e Portrait des Traductrices (Delisle, 2002), nos quais as carreiras e as traduções de tradutores e tradutoras são comentadas. Mas especialistas brasileiros estão começando a examinar a obra e biografias de tradutores brasileiros, e às vezes os resultados são surpreendentes: Oliveira e Martins (no prelo) descrevem a atividade tradutora de Dom Pedro II, Imperador do Brasil, e no presente volume Alessandra Harden analisa as traduções de obras científicas do tradutor brasileiro Manoel Jacinto Nogueira da Gama no final do século XVIII. 
O próximo ponto de D’hulst é: Quid? (O quê?) Temos de saber o que foi traduzido no Brasil, para construir um tipo de arqueologia sobre o qual podemos elaborar nossas análises e teorias. O que não foi traduzido? E o que foi escrito sobre a tradução? De quais escolas de crítica vieram esses comentários? Temos a impressão que praticamente nada foi escrito em termos teóricos antes das obras de Paulo Rónai, a partir dos anos 1950. Será que esse é realmente o caso?

Ubi? (Onde?) Onde foram publicadas as traduções? Em La Republique Mondiale des Lettres (1999) Pascale Casanova descreve Paris como a capital mundial das letras até a segunda grande guerra. Desde então Paris perdeu parte de sua hegemonia, mas as grandes capitais ainda atraem tradutores e estudantes de tradução, embora, hoje em dia, com os avanços da Internet, é possível para tradutores morarem longe dos grandes centros. D’hulst também pergunta sobre a distribuição geográfica de teorias sobre a tradução. Nos anos de 1980 e 1990 os cursos, as publicações e as orientações de Rosemary Arrojo e Paulo Ottoni fizeram da Unicamp um centro importante de pesquisas desconstrucionistas ligadas à tradução. Assim, a teoria desconstrutivista teve bastantes seguidores no Brasil, o que não aconteceu em outros países. E a quais departamentos universitários pertencem os estudos sobre a tradução? Rosemary Arrojo e Paulo Ottoni pertenciam ao Departamento de Linguística Aplicada. Na USP, a área que concentra o maior número de estudos sobre a tradução é o Departamento de Letras Modernas; na Universidade de Leuven, é o Departamento de Literatura Comparada.

O quarto ponto destacado por D’hulst é Quibus auxilius? (Quem ajuda?) Quem banca as traduções? Onde os tradutores podem conseguir financiamento, sobretudo os tradutores de obras literárias que não são comerciais? Antigamente, com mecenas ou reis; hoje em dia, nas agências de pesquisa como a FAPESP, na Biblioteca Nacional, ou em grandes empresas, através da Lei Rouanet. O Departamento de Tradução na Turquia é um exemplo de uma maneira pela qual o governo turco incentivou as traduções, criando um departamento governamental que tinha a responsabilidade de traduzir importantes obras para o turco. O plano também tinha um importante elemento político, promovendo a ocidentalização da sociedade turca e o fortalecimento cultural do regime secular (Berk, 2004: 123-147).

Cur? (Por quê?) Por que são feitas as traduções? Às vezes parece haver uma falta de lógica nas decisões editoriais. Por que foram publicadas no Brasil oito traduções de Wuthering Heights e várias traduções dos poemas de John Donne, Charles 
Baudelaire, Edgar Allan Poe e nenhuma dos de Robert Browning e Alfred Lord Tennyson? Uma resposta poderia ser encontrada na importância dos intermediários, os gatekeepers: os editores; os professores de literatura que muitas vezes são tradutores; e os críticos literários. Nem Tennyson nem Browning tiveram intermediários que introduziram sua obra ao público brasileiro. Outra resposta plausível seria o fato de que certas obras são quase obrigatórias em coleções; Wuthering Heights seria uma delas. E uma nova tradução dá ao leitor uma ideia de um produto novo, fresco, “melhor”.

O sexto ponto é Quo modo? (De qual maneira?) Como foram feitas as traduções? Quais eram as normas que os tradutores seguiam? O estudo sobre as traduções do Clube do Livro de obras clássicas traduzidas do inglês e do francês para o português (Milton, 2002) mostrou que os tradutores nunca utilizaram uma linguagem de baixo padrão; sempre mantiveram uma linguagem culta, até nas várias ocasiões em que traduziram o dialeto cockney de Dickens, o dialeto de Yorkshire em Wuthering Heights, o escocês, em Robert Louis Stevenson, e o inglês do sul dos Estados Unidos em Faulkner (p. 50-60).

De onde veio essa norma? Há várias possibilidades: i) a falta de uma tradição do uso de linguagem oral na literatura brasileira; ii) um mercado editorial bastante conservador, com receio de inovar e utilizar linguagem de baixo padrão; iii) o fato de que as traduções muitas vezes circulam num ambiente escolar, onde "o português correto” é enfatizado, e onde a linguagem de baixo padrão é considerada inaceitável; e iv) o fato de que é muito mais fácil para um tradutor utilizar o português padrão do que um português dialetal ou inventar formas “incorretas”. E se esses tradutores recebem por lauda ou palavra, como é o costume, o esforço para inventar ou estudar um dialeto acarretaria em tempo gasto que não seria recompensado.

O sétimo ponto apresentado por D’hulst é Quando? Em quais épocas são feitas as traduções? Por exemplo, o número de traduções publicadas aumentou muito nas décadas de 1930 e 1940, e o período entre 1942 e 1947 foi chamado “A Idade de Ouro da tradução" (Wyler 2003: 129). Nessa época, muitos autores clássicos foram traduzidos pela primeira vez no Brasil. Podemos mencionar as primeiras traduções brasileiras de obras de Thomas Mann, James Joyce, André Gide, Virginia Woolf, Franz Kafka, Aldous Huxley, John Steinbeck, Luigi Pirandello e William Faulkner, lançadas pela Coleção Nobel da Editora Globo de Porto Alegre; e Em busca do tempo perdido, de Marcel Proust, e Guerra e paz, de Leon Tolstoi, publicados pela Biblioteca dos Séculos, também da Editora Globo (Milton, 2003: 23-24). E a Editora José Olympio, do 
Rio de Janeiro, lançou traduções brasileiras de Jane Austen, Mrs. Gaskell, John Galsworthy, Emily Brontë, Honoré Balzac e Leon Tolstoi, entre outros (Hallewell, 1982: 373). Mas por que tantos livros estrangeiros foram publicados nessa época? O artigo "The importance of economic factors in translation publication: an example from Brazil” (Milton, 2008) enfatiza a importância de fatores econômicos na produção de traduções: as barreiras alfandegárias encareceram o preço de livros importados; havia uma classe média crescente com certo poder aquisitivo, mas sem conhecimento de línguas estrangeiras; e em certos casos o filme produzido em Hollywood atraía os leitores para ler o romance: 39 Steps, de John Buchan, Wuthering Heights, de Emily Brontë e Pride and Prejudice, de Jane Austen, são bons exemplos (Hallewell, 1982: 374-375).

O oitavo e último ponto é Cui Bono? (Para quem?) Essa área, que enfoca a recepção das traduções e o uso que delas se faz, é muito pouco estudada. Quem lê traduções? Faltam estudos sobre seus leitores. As traduções formam uma parte integral de nossa sociedade: diariamente lidamos com comerciais, bulas de empresas multinacionais, relatórios empresariais, notícias de jornais, que em muitos casos foram traduzidas, resumidas ou adaptadas de fontes estrangeiras.

A esquematização de D’hulst deixa transparecer muitas das lacunas e possíveis caminhos para a pesquisa historiográfica sobre a tradução no Brasil. Faltam estudos sobre a importância da tradução dentro das editoras. Como são tomadas as decisões dentro da editora, e por quem? Qual é o relacionamento entre a editora e os tradutores? Aqui podemos mencionar os estudos de Hélène Buzelin, que utilizam como base a Actor Network Theory para analisar as decisões tomadas dentro de uma editora quebequense (Buzelin, 2005).

Nossa arqueologia brasileira ainda é pouco firme. Não sabemos o que foi traduzido, por quem, quando e onde. Por exemplo, quais traduções foram publicadas na década de 1910? Há alguns estudos que traçam as várias traduções de uma obra, ou de um autor. Irene Hirsch, por exemplo, descreveu a história das traduções brasileiras de Moby Dick (Hirsch, 2003) e Marcia Martins (1999 e 2008), as da poesia dramática shakespeariana. Neste volume, Silvia Cobelo enfoca os seis tradutores do Quixote publicados no Brasil e Denise Bottman aborda a presença de Edgar Allan Poe também em nosso sistema cultural.

A tradução pode ser uma ferramenta poderosa. Em "Translation and Americanism in Brazil 1920-1970" (Hirsch \& Milton, 2005) discute-se o enorme 
investimento norte-americano em traduções no Brasil nos anos de 1960 e 1970, especialmente de livros didáticos da Editora McGraw-Hill, para serem utilizados em faculdades e cursos técnicos nas áreas de administração, marketing, economia etc. Assim, a tradução foi a maneira pela qual a dominação norte-americana afirmou-se nessas áreas.

Lia Wyler, em “Translating Brazil” (2001a), descreve o Brasil bilíngue antes do decreto do Marquês de Pombal em 1758, quando a maioria da população falava nheengatu, ou a língua geral, um tipo de tupi. Mas não temos dados sobre a quantidade enorme de atividade tradutória que provavelmente ocorreu. No mesmo volume, Tânia Brandão (2001) e Lia Wyler (2001b) escrevem sobre o predomínio de traduções e adaptações de peças francesas no teatro brasileiro no século XIX.

Há áreas da história de tradução totalmente virgens, dentro e fora do Brasil. Entre elas podemos mencionar a história do ensino de tradução; a história da interpretação; a história da tradução na mídia; e a tradução e interpretação nas comunidades de imigrantes: aqui no Brasil não existem estudos sobre a tradução dentro das comunidades italiana, alemã, japonesa, russa, ucraniana, polonesa, chinesa, coreana etc, e a tradução entre as línguas indígenas e o português.

Assim, na expectativa de contribuir para a historiografia da tradução no contexto brasileiro ou de outros sistemas culturais, Tradução em Revista lança agora um número temático com artigos enfocando vários dos aspectos mencionados por D'hulst (2001). Essas contribuições se inter-relacionam de várias formas, mas o que logo chama a atenção neste conjunto de reflexões é o destaque dado à figura do tradutor (Quis?). Dos oito trabalhos, cinco se debruçam sobre a produção seja de um determinado tradutor, como nos casos de Nogueira da Gama e Ugo Foscolo, seja de um grupo, como os tradutores brasileiros de D. Quixote, os tradutores da época da expansão marítima em Portugal e os tradutores que traduzem suas próprias obras, os chamados autotradutores. Pode-se dizer que Quis? também é um foco importante do texto que aborda a presença de Poe no Brasil, por problematizar o caso de traduções idênticas atribuídas a diferentes tradutores.

O conjunto de textos aqui reunido poderia ser organizado de várias formas: seguindo uma linha no tempo, começando pelo período dos grandes descobrimentos em Portugal e chegando até os dias de hoje, com as traduções e autotraduções contemporâneas; adotando o critério geográfico, pelo qual consideram-se afins as reflexões que enfocam, de um lado, especificamente o contexto brasileiro, e de outro, 
um ou mais sistemas culturais estrangeiros; ou, ainda, recorrendo ao viés temático, segundo o qual quatro focos principais se destacariam: a tradução científica, a história das traduções ou da produção de determinados tradutores, a história de um tipo de reescrita (autotradução) e a teoria de tradução predominante em uma dada época (Renascimento). No ensaio "History and Translation", que integra o Companion to Translation Studies (Kuhiwczak \& Littau, 2007), coletânea que aborda diferentes aspectos da tradução e suas interfaces com outras disciplinas a partir de uma visada retrospectiva, que avalia os caminhos da discplina Estudos da Tradução nas últimas décadas, Lynne Long observa que a história da tradução é algumas vezes apresentada como sendo unicamente a história das teorias de tradução, embora essa proposta deixe de contemplar grande parte do território a ser explorado (p. 13). Inclui-se, aqui, a atividade tradutória destinada a promover a aquisição e a expansão do conhecimento, que pode se desenvolver sob forma de projetos dos mais modestos aos mais ambiciosos, como os ocorridos em Bagdá, dos séculos VIII a X, e em Toledo, no século XIII.

Diante, portanto, da predominância dos estudos sobre a história das teorias de tradução (e também sobre a das traduções literárias, como evidencia a bibliografia disponível) e da consequente escassez de pesquisas sobre tradução científica, optamos pela organização temática, que torna mais visível a afinidade entre as contribuições que tratam da transmissão do conhecimento científico.

Em seu texto "A tradução de textos científicos no período da expansão marítima, uma história em construção", Cristina de Amorim Machado apresenta alguns resultados atualizados sobre o papel da tradução na expansão marítima, partindo da hipótese de que a tradução teve um papel de destaque nesse empreendimento ibérico, sobretudo na transmissão dos textos científicos antigos. Alessandra Ramos de Oliveira Harden, no cenário do fenômeno ocorrido em Portugal no final do século XVIII, que se caracterizou pela publicação de grande número de obras traduzidas em áreas como matemática, química e biologia, detém-se sobre o papel desempenhado nesse movimento pelo brasileiro Manoel Jacinto Nogueira da Gama, futuro Marquês de Baependi, Ministro da Fazenda e signatário da Constituição de 1824. Harden examina os prefácios que Nogueira da Gama escreveu para suas traduções com vistas a depreender suas opiniões sobre as relações entre tradução, língua e ciência no contexto do Iluminismo Português. Por sua vez, Cristina Carneiro Rodrigues, em "O papel da tradução na pesquisa científica brasileira: primeiros movimentos", examina o Brasil da Era Vargas para verificar qual foi o papel das traduções na construção da ciência brasileira. Em seu 
percurso, aborda o estabelecimento das universidades como centros de investigação científica e sua relação com a expansão editorial naquele período histórico, especialmente com a publicação de coleções de obras não-ficcionais; o lançamento de títulos de "Coleções Brasilianas"; e o papel das traduções como fonte de referência para pesquisadores de várias áreas do conhecimento, como as geociências, a botânica, a biologia e a história.

No segundo grupo de textos, que enfocam a história das traduções ou da produção de determinados tradutores, Karine Simoni trata de aspectos da história da tradução dos clássicos na Itália nos séculos XVIII e XIX, de modo a apresentar um panorama das aproximações e embates entre os principais tradutores do período, com destaque para Ugo Foscolo. O artigo destaca também o pensamento de Foscolo e as suas principais contribuições para os estudos da tradução. A seguir, já no sistema cultural brasileiro, temos "Os tradutores do Quixote publicados no Brasil", em que Silvia Cobelo reúne a história dos seis tradutores do Quixote desde 1942, data da primeira edição brasileira da obra, até 2008, e "Alguns aspectos da presença de Edgar Allan Poe no Brasil", de Denise Bottman, que aborda a primeira edição brasileira de contos de Poe, as traduções de The Black Cat e as várias antologias de seus contos sempre agrupados sob o título de Histórias extraordinárias.

Completam este volume as contribuições de Maria Alice G. Antunes e Mauri Furlan, que se debruçam, respectivamente, sobre uma modalidade de tradução — a autotradução, ou seja, aquela realizada pelo próprio autor - e sobre uma teoria de tradução renascentista, a teoria elocutiva. Em "Breve história da autotradução: os casos de André Brink e João Ubaldo Ribeiro", Antunes apresenta um resumo da história da autotradução desde o século I até o século XXI, com destaque para os casos do escritor sul-africano André Brink e o do brasileiro João Ubaldo Ribeiro, por meio dos quais procura demonstrar como a autotradução é uma atividade exercida de maneiras distintas, com propósitos igualmente distintos. No trabalho "Da teoria elocutiva da tradução renascentista" Furlan também enfoca estratégias tradutórias, mas com o objetivo de reconhecer as características da tradução renascentista e compor uma teoria da tradução vigente nos séculos XV e XVI, caracterizada pela valorização e respeito ao texto original.

Esperamos, assim, avançar um pouco mais na construção de uma história da tradução, em um movimento compatível com uma "virada historiográfica" nos Estudos da Tradução nos moldes da "virada cultural" dos anos 1990 e da "virada política" que 
veio algum tempo depois. Como dizem Kuhiwczak e Littau na apresentação do já mencionado Companion to Translation Studies (2007), agora a disciplina busca um novo conhecimento de si mesma voltando-se para a história: seja a sua história como disciplina, a história das teorias de tradução, o papel que a tradução desempenhou na história do livro ou da indústria editorial, ou uma história sociocultural dos tradutores ${ }^{1}$ (p. 5). Neste volume estão contempladas essas duas últimas vertentes, em uma tentativa de cobrir uma pequena parte do imenso território ainda a ser explorado.

\section{Referências}

BERK, Özlem. Translation and Westernisation in Turkey: from the 1840s to the 1980s. Istambul: Yayinlari, 2004

BRANDÃO, Tânia. Translation and Ellipses: Notes on the 19th Century Brazilian Theatre. Crop, v.6, Número especial: Emerging Views on Translation History in Brazil. Org. John Milton, p. 91-107, 2001.

BUZELIN, Hélène. Unexpected Allies: How Latour's Network Theory Could Complement Bourdieusian Analyses in Translation Studies. The Translator, Volume 11, Number 2, 2005, 193-218.

CASANOVA, Pascale. La Republique Mondiale des Lettres. Paris: Gallimard. 1999.

DELISLE, Jean (Org.) Portraits des traducteurs. Ottawa/Artois: Les Presses de l’Université d’Ottawa; Artois Presses Université, 1999.

DELISLE, Jean (Org.) Portraits des traductrices. Ottawa/Artois: Les Presses de l’Université d’Ottawa; Artois Presses Université, 2002.

DELISLE, Jean; WOODSWORTH, Judith (Eds.) Translators through History. Amsterdam: John Benjamins; Unesco Publishing, 1995.

D’HULST, Lieven. Why and How to Write Translation Histories. Crop, v.6, Número especial: Emerging Views on Translation History in Brazil. Org. John Milton, p. 21-32, 2001.

HALLEWELL, Laurence. 1982. O Livro no Brasil. São Paulo: Queiroz.

HIRSCH, Irene. Translations of Herman Melville in Brazil. Crop, v.6, Número especial: Emerging Views on Translation History in Brazil. Org. John Milton, p. 129-142, 2001.

\footnotetext{
${ }^{1}[\ldots]$ the discipline seeks a new understanding of itself by turning to history: be this its history as a discipline, the history of theories of translation, the role that translation has played in book and publishing history, or a socio-cultural history of the translator.
} 
HIRSCH, Irene; MILTON, John. Translation and Americanism in Brazil 1920-1970, in Across: Language and Cultures, Volume 6, Issue 2. Akadémiai Kiadó, Budapest, p. 234-257, 2005.

KUHIWCZAK, Piotr; LITTAU, Karin. Introduction. In: (Eds.). A Companion to Translation Studies. Topics in Translation 34. Clevedon, UK: Multilingual Matters, 2007. p. 1-12.

MARTINS, Marcia A.P. A instrumentalidade dos estudos descritivos para a análise de traduções: o caso dos Hamlets brasileiros. São Paulo, 1999. 324p. Tese (Doutorado em Comunicação e Semiótica) - Programa de Estudos Pós-Graduados em Comunicação e Semiótica, Pontifícia Universidade Católica de São Paulo.

. Shakespeare em tradução no Brasil. In: LEÃO, Liana de Camargo; SANTOS, Marlene Soares dos (Orgs.) Shakespeare, sua época e sua obra. Curitiba: Beatrice, 2008. p. 301-319.

MARTINS, Marcia A.P.; OLIVEIRA, Anna Olga Prudente de. D. Pedro II, MonarcaTradutor. TradTerm, v. 17. Número Especial: Brasil: História, Sociedade, Tradução. Org. John Milton; Irene Hirsch. No prelo.

MILTON, John. The Translations of the Brazilian Book Club, the Clube do Livro. Crop, v.6. Número especial: Emerging Views on Translation History in Brazil. Org. John Milton, p.195-245, 2001a.

The Translation of Classic Fiction for Mass Markets. The Case of a Brazilian Book Club, the Clube do Livro. The Translator, Volume 7, Number 1, 2001, p. 43-69, $2001 b$.

O Clube do Livro e a Tradução. Bauru: Editora da Universidade do Sagrado Coração (EDUSC), 2002.

The importance of economic factors in translation publication: an example from Brazil. In: PYM, Anthony; SHLESINGER, Miriam; SIMEONI, Daniel (Eds.) Beyond Descriptive Translation Studies: Investigations in Homage to Gideon Toury. Amsterdam: John Benjamins, 2008. p.163-173.

PELEGRIN, Laureano. Tradutores e editores: resistência, restrições, relações. São Paulo, 2002. Dissertação (Mestrado em Estudos Linguísticos e Literários em Inglês) - Faculdade de Filosofia, Letras e Ciências Humanas, Universidade de São Paulo.

SIMEONI, Daniel. The Pivotal Status of the Translator's Habitus, Target 10(1), p. 139, 1998.

WYLER, Lia. Translating Brazil. Crop, v.6, Número especial: Emerging Views on Translation History in Brazil. Org. John Milton, p. 33-50, 2001a.

Theatre, Translation and Colonization. Crop, v.6, Número especial: Emerging 
Views on Translation History in Brazil. Org. John Milton, p.75-90, 2001b.

Línguas, poetas e bacharéis: uma crônica da tradução no Brasil. Rio de Janeiro: Rocco, 2003. 